\title{
Evidence-based guideline summary: Evaluation, diagnosis, and management of facioscapulohumeral muscular dystrophy
}

Report of the Guideline Development, Dissemination, and Implementation Subcommittee of the American Academy of Neurology and the Practice Issues Review Panel of the American Association of Neuromuscular \& Electrodiagnostic Medicine [0 妵全

Rabi Tawil, MD

John T. Kissel, MD

Chad Heatwole, MD, MS-CI

Shree Pandya, PT, DPT, MS

Gary Gronseth, MD

Michael Benatar, MBChB, DPhil

Correspondence to American Academy of Neurology: guidelines@aan.com

Supplemental data at Neurology.org

\section{ABSTRACT}

Objective: To develop recommendations for the evaluation, diagnosis, prognostication, and treatment of facioscapulohumeral muscular dystrophy (FSHD) from a systematic review and analysis of the evidence.

Methods: Relevant articles were analyzed in accordance with the American Academy of Neurology classification of evidence schemes for diagnostic, prognostic, and treatment studies. Recommendations were linked to the strength of the evidence and other factors.

Results and recommendations: Available genetic testing for FSHD type 1 is highly sensitive and specific. Although respiratory insufficiency occurs rarely in FSHD, patients with severe FSHD should have routine pulmonary function testing. Routine cardiac screening is not necessary in patients with FSHD without cardiac symptoms. Symptomatic retinal vascular disease is very rare in FSHD. Exudative retinopathy, however, is potentially preventable, and patients with large deletions should be screened through dilated indirect ophthalmoscopy. The prevalence of clinically relevant hearing loss is not clear. In clinical practice, patients with childhood-onset FSHD may have significant hearing loss. Because undetected hearing loss may impair language development, screening through audiometry is recommended for such patients. Musculoskeletal pain is common in FSHD and treating physicians should routinely inquire about pain. There is at present no effective pharmacologic intervention in FSHD. Available studies suggest that scapular fixation is safe and effective. Surgical scapular fixation might be cautiously offered to selected patients. Aerobic exercise in FSHD appears to be safe and potentially beneficial. On the basis of the evidence, patients with FSHD might be encouraged to engage in low-intensity aerobic exercises. Neurology ${ }^{\circledR} 2015 ; 85: 357-364$

\section{GLOSSARY}

AAN = American Academy of Neurology; $\mathbf{C l}$ = confidence interval; FSHD = facioscapulohumeral muscular dystrophy; FSHD2 = facioscapulohumeral muscular dystrophy type 2; $\mathbf{M D}=$ muscular dystrophy; poly-A = polyadenylation; $\mathbf{Q O L}=$ quality of life.

Facioscapulohumeral muscular dystrophy (FSHD) is the third most common form of muscular dystrophy (MD), with a prevalence of approximately 1:15,000 $1: 20,000 .^{1,2}$ It is an autosomal dominant disorder; however, up to $30 \%$ of cases are sporadic, arising from de novo mutations.

FSHD symptoms typically develop in the second decade of life but can begin at any age from infancy to late adulthood. ${ }^{1}$ FSHD is characterized by a distinctive, initially regional distribution of muscle involvement. Facial, periscapular, and humeral muscles typically are involved early in the disease course, although the deltoids are spared. ${ }^{3}$ FSHD typically progresses slowly but variably. ${ }^{4,5}$ About $20 \%$ of individuals with FSHD become wheelchair dependent after age $50 .{ }^{1}$

Extramuscular manifestations occur in FSHD and can include respiratory compromise; retinal vascular

\footnotetext{
From the MDA Neuromuscular Disease Clinic (R.T.) and the Department of Neurology (C.H., S.P.), School of Medicine and Dentistry, University of Rochester Medical Center, NY; the Department of Neurology (J.T.K.), Wexner Medical Center, Ohio State University, Columbus; the Department of Neurology (G.G.), University of Kansas School of Medicine, Kansas City; and the Department of Neurology (M.B.), Miller School of Medicine, University of Miami, OH.

This document summarizes extensive information provided in the complete guideline, available as a data supplement on the Neurology ${ }^{\circledR}$ Web site (Neurology.org). Appendices e-1 through e-6 are available in the complete guideline document; references e1 through e34, cited herein, are available at Neurology.org.

Approved by the Guideline Development, Dissemination, and Implementation Subcommittee on July 23, 2014; by the AAN Practice Committee on October 20, 2014; by the AANEM Board of Directors on April 13, 2015; and by the AANI Board of Directors on March $24,2015$.

This guideline was endorsed by the FSH Society on December 18, 2014.

Go to Neurology.org for full disclosures. Funding information and disclosures deemed relevant by the authors, if any, are provided at the end of the article.
} 
disease that, rarely, leads to exudative retinopathy and visual loss; hearing loss; and, possibly, increased incidence of cardiac arrhythmias.

The molecular genetic basis of FSHD is complex. At the tip of chromosome $4 \mathrm{q} 35$ lies a repetitive 3.3 kilobase (kb) DNA sequence known as D4Z4 repeats. ${ }^{6,7}$ Moreover, there are 2 different DNA variants distal to the $\mathrm{D} 4 \mathrm{Z} 4$ repeats, called the $\mathrm{A}$ and $\mathrm{B}$ allelic variants. ${ }^{8}$ FSHD type 1 (FSHD1), accounting for 95\% of FSHD cases, results from deletion of a critical number of D4Z4 repeats, but only when this occurs on the A allele. The biological basis for this dual requirement is becoming increasingly understood. Contraction of the $\mathrm{D} 4 \mathrm{Z} 4$ repeat results in a more open chromatin structure, allowing the potential expression of gene sequences within the repeats. One such gene, double homeobox 4 (DUX4), lacks the polyadenylation (poly-A) sequence required to produce stable messenger RNA. ${ }^{9,10}$ Because only the A (not the B) allele variant contains a poly-A sequence, stable DUX4 expression can occur only in the presence of the A allelic variant. ${ }^{11,12}$

Complicating matters is the existence of a genetically distinct but clinically identical FSHD typeFSHD type 2 (FSHD2) - now known to account for approximately $5 \%$ of patients with clinically defined FSHD. ${ }^{13,14}$ Unlike the majority of patients with FSHD (i.e., FSHD1), patients with FSHD2 do not have contractions in the 4q35 D4Z4. As with FSHD1, and despite a normal number of repeats, the chromatin structure at the $\mathrm{D} 4 \mathrm{Z} 4$ repeats is more open, and at least one $4 \mathrm{q} 35$ allele is an A variant. ${ }^{13}$ Recent studies have implicated mutations in SMCHD1, a gene on chromosome 18 that functions as a chromatin modifier, as the cause of the D4Z4 chromatin changes observed in about $85 \%$ of patients with FSHD2. ${ }^{15}$ Comprehensive molecular genetic testing for FSHD2 is complex and not readily available currently, and thus is not addressed herein.

Despite having distinct genotypes, FSHD1 and FSHD2 have an identical molecular basis that results from the aberrant expression of the DUX4 gene in skeletal muscle. ${ }^{11,15}$ DUX4 protein is a transcription factor normally expressed only in the germline, but little is known about its function. ${ }^{16}$ Preliminary evidence suggests that inappropriate expression of DUX4 and its transcriptional targets in skeletal muscle can result in apoptosis, impaired muscle regeneration, and induction of an immune response. ${ }^{16}$

Previous FSHD practice guidelines have been based on expert opinion. ${ }^{17,18}$ The present guideline, based on systematic review of the evidence, focuses exclusively on FSHD. Duchenne MD and myotonic dystrophy will be discussed in forthcoming guidelines; limbgirdle MD and congenital MD are addressed in separate guidelines. ${ }^{19,20}$ The present guideline addresses the following practical issues related to FSHD (reflective only of evidence relevant to FSHD1; no large FSHD2 clinical studies exist):

1. For patients with clinically defined FSHD (as determined by explicitly stated clinical criteria substantially similar to the consortium criteria), ${ }^{21}$ how often does D4Z4 contraction on 4q35 confirm diagnosis of FSHD (irrespective of presence of allele A)? For individuals who do not have FSHD, how often is a D4Z4 contraction on $4 \mathrm{q} 35$ found, and how often is a D4Z4 contraction on $4 \mathrm{q} 35$ on allele $A$ found?

2. Which factors are associated with or predict loss of clinically meaningful milestones (e.g., loss of independent ambulation)?

3. How frequent are respiratory abnormalities, cardiac abnormalities, retinal disease, hearing loss, and pain?

4. Do interventions (as compared with no intervention) improve patient-relevant outcomes? Are there features that identify patients who are more or less likely to improve with a specific intervention?

DESCRIPTION OF THE ANALYTIC PROCESS The methods used to develop this guideline are detailed in the complete guideline (see data supplement on the Neurology ${ }^{\circledR}$ Web site at Neurology.org). In brief, the American Academy of Neurology (AAN) convened an author panel of clinicians with FSHD expertise. The panel systematically reviewed the evidence relevant to the posed questions according to the processes described in the 2004 and 2011 AAN process manuals. ${ }^{22,23}$ The panel formulated practice recommendations based on the evidence systematically reviewed, stipulated axiomatic principles of care, strong evidence from closely related conditions, and judgments regarding risk-benefit and patient preferences.

\section{ANALYSIS OF EVIDENCE FSHD genetic testing.} Understanding the molecular genetics of FSHD1 is critical to molecular diagnosis of this disorder. Healthy individuals possess at least 11 D4Z4 repeats, yielding a DNA fragment $>38 \mathrm{~kb}$ on standard genetic testing. Affected individuals, in contrast, possess $1-10$ repeats, yielding DNA fragments $10-38 \mathrm{~kb}$ in size. ${ }^{7}$ Measurement of the size of the residual D4Z4 sequence on $4 \mathrm{q} 35$ forms the basis for genetic testing in FSHD. As previously discussed, FSHD identification also requires that the contraction occur on the A allelic variant. Routine first-pass commercial genetic testing in the United States measures the residual D4Z4 repeat sizes without determining the A or B allelic variants. The prevalence of D4Z4 repeat sizes ranging from 1 to 10 alleles is low in the general 
population. This low prevalence raises questions about the clinical utility of routine determination of the $\mathrm{A} / \mathrm{B}$ variant in molecular confirmation of FSHD.

Our systematic review identified 9 Class III studies $^{24-32}$ from specialty clinics that, together, demonstrate that the finding of a D4Z4 contraction on chromosome $4 \mathrm{q} 35$ likely has a sensitivity of $93 \%$ and a specificity of $98 \%$ for diagnosis of clinically defined FSHD. In a patient population with clinically defined FSHD, the degree of specificity is unlikely to be further enhanced by testing for presence of the A variant.

Risk factors for disease severity. In any neuromuscular disorder, a critical aspect of patient management lies in identifying clinical, biochemical, or genetic aspects of the illness associated with prognosis. It is indispensable to identify such risk factors that might be linked to a severe (or more benign) course when discussing prognosis with patients, designing therapy programs and other meaningful interventions, and helping patients make important medical, financial, and other life decisions. This is true particularly in a disease such as FSHD where extent and severity of involvement vary tremendously.

D4Z4 repeat size. The systematic review identified one Class I study ${ }^{33}$ demonstrating that in patients with FSHD, smaller D4Z4 repeat size is probably associated with more severe disease as measured by age at diagnosis and age at wheelchair dependence. Class II and Class III studies ${ }^{29,34-36}$ provided evidence that smaller fragment size is possibly associated with other measures of disease severity, including early age at onset, quantitative computerized muscle testing, severity of leg weakness, global severity scores, and earlier loss of ambulation.

Age at onset. One Class III study ${ }^{34}$ demonstrated that earlier age at onset appears to be associated with earlier loss of ambulation (as well as smaller fragment size).

Complications. Although the cardinal features of FSHD involve limb weakness that starts with focal weakness of the shoulders, face, and humeral muscles, additional systemic features may occur. These extramuscular features may have significant and, at times, life-threatening consequences.

Respiratory abnormalities. Evidence from one Class II study ${ }^{37}$ and one Class III study ${ }^{38}$ suggests that respiratory insufficiency and reduced pulmonary function may occur, with estimated frequencies varying from $1.25 \%$ (95\% confidence interval [CI] $0.5 \%-2 \%)$ to $13 \%$ (95\% CI $0.7 \%-27 \%)$. Given the imprecision of these estimates and the quality of the evidence, we cannot reliably estimate the frequency and severity of respiratory compromise in patients with FSHD.
Cardiac abnormalities. Four Class III electrocardiographic/echocardiographic studies found no structural abnormalities in 80 patients with FSHD (95\% CI $0 \%-4.6 \%),{ }^{39,40, \mathrm{e} 1, \mathrm{e} 2}$ indicating that the frequency of structural cardiac abnormalities on electrocardiography/echocardiography may be low. Six Class III studies examining the frequency of symptomatic or inducible supraventricular arrhythmias in patients with $\mathrm{FSHD}^{38-\mathrm{e} 3}$ found these arrhythmias in $9.7 \%$ (95\% CI $6.5 \%-14.2 \%$ ). Because of risk of referral bias in these studies, data are insufficient to reliably determine the frequency of clinically relevant cardiac abnormalities.

Retinal vascular disease. The combined results from 4 Class III studies ${ }^{\mathrm{e}-\mathrm{e}} 7 \mathrm{demonstrated}$ that up to $25 \%$ (95\% CI 20.9\%-30.8\%) of patients with FSHD had abnormalities on retinal examination and $0.6 \%$ (95\% CI $0.2 \%-1.5 \%$ ) had symptomatic retinal disease.

Hearing loss. Eight Class III studies using audiometry to examine hearing demonstrated that $15.5 \%$ (95\% CI 12.1\%-19.4\%) had audiometric abnormalities. $^{25,32, \mathrm{e}-\mathrm{e} 10}$ In addition, hearing loss occurs only in patients with large deletions ( $\leq 20 \mathrm{~kb}$ ); 32\% (95\% CI $16.7 \%-51.4 \%$ ) of patients in this group have hearing loss. ${ }^{\text {el0 }}$ Confidence in the evidence for prevalence of audiometric abnormalities is very low due to the wide range of frequencies.

Pain. One Class II study and 2 Class III studies ${ }^{\text {e1 } 1-e 13}$ observed that up to $79 \%$ (95\% CI $74.6 \%-82.8 \%$ ) of patients with FSHD complained of pain. The most common sites of pain are, in descending order, the lower back, legs, shoulders, and neck. ${ }^{\text {e12 }}$ A single Class III study assessing pain severity noted that $10.8 \%$ (95\% CI 3.2\%-18.3\%) of patients had clinically significant pain. ${ }^{\mathrm{e} 1}$

Treatment. The goal of therapy in FSHD is to improve muscle strength or function, or both. Until recently the underlying pathophysiology of FSHD was unknown, and thus pharmacologic trials have focused on improving muscle mass and strength, whereas surgical studies of scapular fixation have been motivated by efforts to improve function notwithstanding the presence of weakness.

Pharmacologic interventions. Based on 2 Class I studies examining the effect of oral albuterol on strength in FSHD, ${ }^{\mathrm{e} 14, \mathrm{e} 15}$ it is highly likely that albuterol is ineffective for improving muscle strength. Data are insufficient to judge the efficacy of albuterol for muscle pain and fatigue. ${ }^{\mathrm{e} 16}$

A Class I study of the effect of an IV myostatin inhibitor (MYO-029) demonstrated no significant improvement in muscle strength. Data are insufficient to support or refute the effects of prednisone (1 Class IV study) $)^{\mathrm{e} 17, \mathrm{e} 18}$ or diltiazem (1 Class IV study) ${ }^{\mathrm{e} 19}$ on muscle strength. 
Surgical scapular fixation. One Class III study and 10 Class IV uncontrolled case series ${ }^{\mathrm{e} 20-\mathrm{e} 30}$ used different surgical approaches and demonstrated consistent responses on measures of shoulder function to scapular fixation. These studies indicated that scapular fixation is possibly effective for improving shoulder abduction and anterior flexion.

Exercise. One Class I study examining the effect of strength training on muscle strength demonstrated no evidence of improved isometric strength testing; however, it reported improvement of significant but questionable importance in dynamic strength in 1 of 2 muscle groups tested. ${ }^{16}$ This study supported the conclusion that strength-training exercise is probably ineffective for improving muscle strength meaningfully.

A single Class III study ${ }^{\text {e31 }}$ provided very weak evidence that low-intensity aerobic exercise improved both workload (by 17\%; standard deviation 4, $p<$ 0.002 ) and self-reported levels of activity, without evidence of muscle damage.

PRACTICE RECOMMENDATIONS The recommendations below encompass 4 major areas: diagnosis, predictors of severity, surveillance for complications, and treatment. A clinical context section precedes each recommendation, and outlines the evidence, general principles of care, and evidence from related disorders that inform the recommendations.

Diagnosis of FSHD. See also the algorithm in the figure.

Clinical context. When clinical presentation of FSHD is typical and the inheritance pattern is consistent with autosomal dominant inheritance, clinical diagnosis is usually straightforward. If, in such circumstances, the diagnosis is genetically confirmed in a first-degree relative, genetic testing is not necessary for each affected individual. However, atypical presentations are not uncommon. In the setting of atypical or sporadic cases, genetic confirmation is important for genetic counseling, especially with the recent discovery of 2 genetically distinct forms of FSHD.

In the most common FSHD type, FSHD1, disease results from contraction of a DNA repeat sequence, termed D4Z4 repeat, on 1 copy of $4 \mathrm{q} 35$ from $>10$ repeats to $1-10$ repeats. In addition, the contraction must occur in the presence of 1 particular (A variant) of 2 (A/B) sequence variants distal to the repeats. Available molecular testing for FSHD1, which measures only the presence of a repeat contraction on initial testing, is highly sensitive and specific. In studies that utilized strict diagnostic criteria for FSHD, determining whether a contraction occurs on an A variant genetic background does not appear to improve diagnostic specificity. However, in clinical practice, strict clinical diagnostic criteria might not be adhered to, increasing the chances of a false-positive result. In consequence, determining that a D4Z4 contraction is occurring on an A variant is warranted when the clinical presentation is atypical for FSHD. At present, commercial genetic testing in FSHD is limited to FSHD1 testing.

Recommendation. Clinicians should obtain genetic confirmation of FSHD1 in patients with atypical presentations and no first-degree relatives with genetic confirmation of the disease (Level B). The figure shows the recommended FSHD molecular diagnosis decision tree.

Predictors of severity in FSHD. Clinical context. Factors that predict disease severity in FSHD are important for counseling patients and for screening for and managing potential complications. The D4Z4 deletion size appears to be somewhat predictive of the overall rate of disease progression. D4Z4 deletion size should be used cautiously for predicting disease progression rate in any particular individual due to other sources of variation affecting disease severity, including intrafamilial factors. Clinical experience suggests that patients with severe childhood-onset disease almost invariably have very large deletions (i.e., contracted D4Z4 allele of 10-20 kb or 1-4 repeats), suggesting a much more robust correlation between disease severity and large deletions.

Recommendation. Large D4Z4 deletion sizes (contracted D4Z4 allele of $10-20 \mathrm{~kb}$ ) should alert the clinician that the patient is more likely to develop more significant disability and at an earlier age. Patients with large deletions are also more likely to develop symptomatic extramuscular manifestations (Level B) (see next section on Monitoring for complications of FSHD).

Monitoring for complications of FSHD. Pulmonary complications. Clinical context. Our systematic review revealed that some patients with FSHD develop respiratory muscle weakness that can result in respiratory failure and need for mechanical ventilator assistance (e.g., nocturnal bilevel positive airway pressure), although this complication is uncommon. $\mathrm{Pa}-$ tients with chronic respiratory failure from neuromuscular-related weakness often do not have classic symptoms of ventilatory failure (i.e., overt dyspnea). Impending respiratory failure, therefore, may begin with respiratory insufficiency mainly during sleep, resulting in excessive daytime somnolence or nonrestorative sleep. Respiratory insufficiency in patients with FSHD, therefore, may be evident only through pulmonary function testing. Respiratory failure constitutes a major source of morbidity in patients with most MD types and can severely disrupt sleeping, daily activities, and 
Figure Recommended diagnostic flowchart for facioscapulohumeral muscular dystrophy

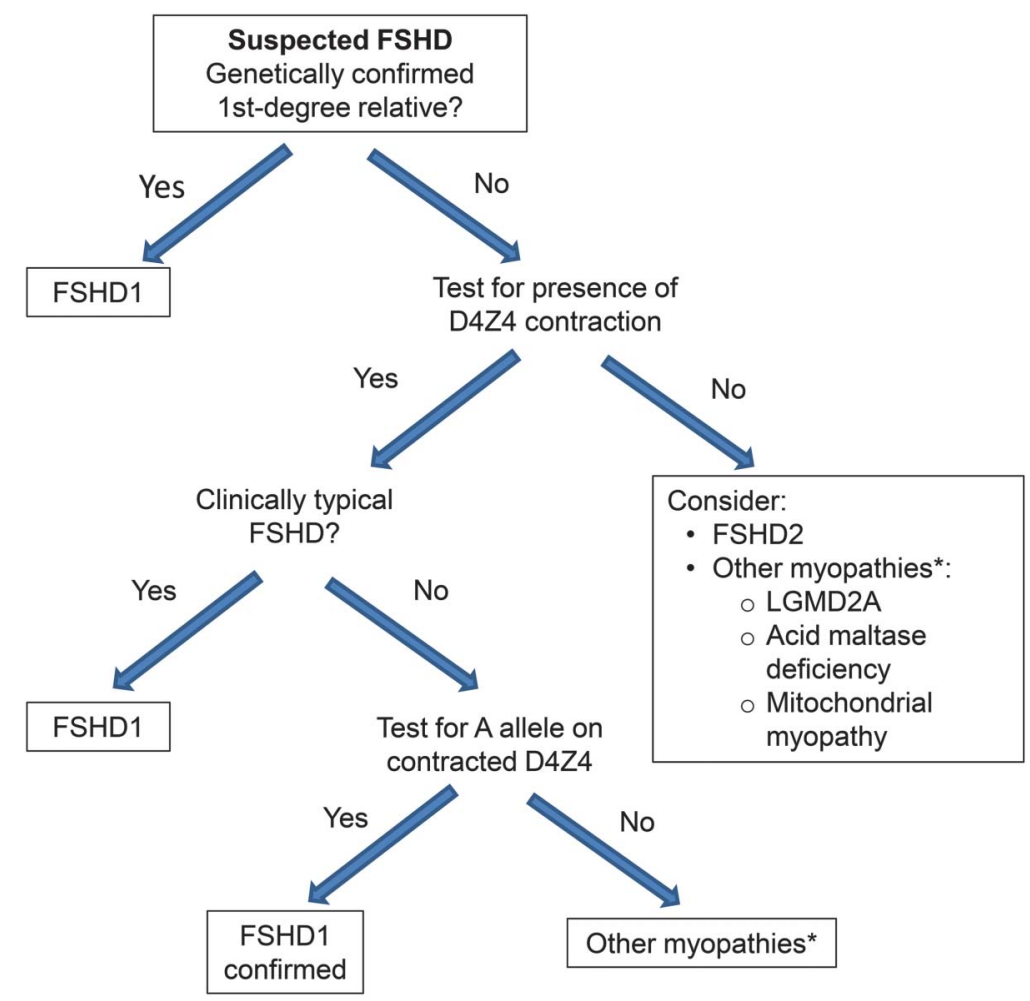

def $=$ deficiency; FSHD = facioscapulohumeral muscular dystrophy; FSHD1 = facioscapulohumeral muscular dystrophy type 1; FSHD2 = facioscapulohumeral muscular dystrophy type 2; LGMD2A = limb-girdle muscular dystrophy type 2A.

quality of life (QOL). Early intervention with noninvasive mechanical ventilation leads to improved survival and QOL. ${ }^{\text {32 }}$

Recommendations. Clinicians should obtain baseline pulmonary function tests on all patients with FSHD. Patients should be monitored regularly if they have abnormal baseline pulmonary function test results or any combination of severe proximal weakness, kyphoscoliosis, wheelchair dependence, or comorbid conditions that may affect ventilation (e.g., chronic obstructive pulmonary disease, cardiac disease) (Level B).

In patients who have FSHD and either (1) compromised pulmonary function studies (e.g., forced vital capacity $<60 \%$ ) or (2) symptoms of excessive daytime somnolence or nonrestorative sleep (e.g., frequent nocturnal arousals, morning headaches), clinicians should refer patients for pulmonary or sleep medicine consultation for consideration of nocturnal sleep monitoring or nocturnal noninvasive ventilation in order to improve QOL (Level B).

Patients with FSHD who do not get regular pulmonary function testing should be tested prior to surgical procedures requiring general anesthesia, as such testing may uncover asymptomatic respiratory compromise (Level B).
Cardiac abnormalities. Clinical context. Our systematic review revealed very little evidence for structural cardiac abnormalities in FSHD. Also, data are insufficient to suggest that patients with FSHD are susceptible to cardiac arrhythmias. Routine electrocardiographic/echocardiographic testing is therefore unnecessary in patients with FSHD who are asymptomatic.

Recommendation. Patients with FSHD should be referred for cardiac evaluation if they develop overt signs or symptoms of cardiac disease (e.g., shortness of breath, chest pain, palpitations). However, routine cardiac screening is not essential in the absence of cardiac signs or symptoms (Level C).

Retinal vascular disease. Clinical context. Our systematic review suggests that symptomatic retinal vascular disease in the form of an exudative retinopathy (Coats disease) is very rare in FSHD but tends to affect patients with large deletions almost exclusively. Untreated exudative retinopathy can lead to significant visual loss, which may be prevented by early intervention.

Recommendation. Clinicians should refer patients with FSHD and large deletions (contracted D4Z4 allele of 10-20 kb) to an experienced ophthalmologist (e.g., retina specialist) for dilated indirect ophthalmoscopy (Level B). The presence and severity of retinal vascular disease at initial screening should be used to determine the frequency of subsequent monitoring (Level B).

Hearing loss. Clinical context. Our systematic review shows that the available studies fail to capture the prevalence and clinical relevance of hearing loss in FSHD. In clinical practice, most patients with FSHD and hearing loss requiring the use of a hearing aid have childhood-onset FSHD with large D4Z4 deletions. Two recent studies support this clinical impression. Moreover, one of the studies suggests that hearing loss is progressive in some patients. Adults and older children are cognizant of the hearing loss onset, and therefore intervention can occur early when required. However, failure to detect hearing loss in infants and younger children may significantly delay or impair language development.

Recommendation. Clinicians should screen all young children with FSHD at diagnosis and yearly thereafter until these children start school, as hearing loss may not be present at diagnosis and can be progressive (Level B).

Pain. Clinical context. Pain is a common complaint in FSHD and appears to be mostly musculoskeletal in origin. Pain compounding muscle weakness can have a significant impact on QOL. Physical therapists often can provide insight into the mechanism of 
pain in patients with weakness. Nonsteroidal antiinflammatory medications are useful for acute pain, and antidepressants or antiepileptics for chronic musculoskeletal pain.

Recommendation. Treating physicians should routinely inquire about pain in patients with FSHD. Referral for a physical therapy evaluation may prove helpful as an initial nonpharmacologic intervention. In patients with persistent pain and no contraindications, a trial of nonsteroidal anti-inflammatory medications is appropriate for acute pain and antidepressants or antiepileptics for chronic pain (Level B).

Treatment of FSHD. Pharmacologic interventions. Clinical context. As of this writing, no evidence exists for any effective pharmacologic interventions that improve strength or slow disease progression in FSHD. Randomized, controlled trials of albuterol were negative. Uncontrolled, open-label trials of corticosteroid and diltiazem showed no benefit. A controlled early phase II study of MYO-029, a myostatin inhibitor, also failed to show benefit.

Recommendation. In patients with FSHD, clinicians should not prescribe albuterol, corticosteroid, or diltiazem for improving strength (Level B).

Surgical scapular fixation. Clinical context. In patients with FSHD, limited shoulder range of motion due to periscapular muscle weakness is a major source of functional limitation. Moreover, in many patients, bedside manual scapular fixation can result in significant improvement in shoulder range of motion. Postoperative complications are infrequent but include hemothorax or pneumothorax, pain, infection, nonunion, and reduced lung capacity. Scapular fixation appears to be generally safe and may be effective for improving shoulder range of motion.

Recommendation. Surgical scapular fixation might be offered cautiously to selected patients after careful consideration of the overall muscle impairment in the involved arm, assessment of potential gain in range of motion by manual fixation of the scapula, the patient's rate of disease progression, and the potential adverse consequences of surgery and prolonged postsurgical bracing (Level C).

Aerobic exercise. Clinical context. Aerobic exercise in FSHD appears to be safe and potentially beneficial, as has been shown in many other muscle diseases. ${ }^{\text {e33 }}$ Aerobic fitness is important for overall health. To minimize injury from falls or overuse, the type of aerobic exercise should be tailored to the patient's particular distribution of weakness. For example, a stationary bicycle rather than a treadmill should be recommended for patients with leg weakness. Although no data exist to suggest that strength training is detrimental in FSHD, further research is needed to determine whether such strength training will result in clinically meaningful long-term functional improvement.

Recommendations. Clinicians might encourage patients with FSHD to engage in low-intensity aerobic exercise. An experienced physical therapist can help guide development of individualized exercise programs. Clinicians might also use the practical physical activities guidelines for individuals with disabilities, provided by the US Department of Health and Human Services, when counseling patients about aerobic exercise (Level C). ${ }^{\text {e34 }}$

In patients interested in strength training, clinicians may refer patients to physical therapists to establish a safe exercise program using appropriate low/ medium weights/resistance that takes into consideration the patients' physical limitations (Level C).

\section{AUTHOR CONTRIBUTIONS}

Rabi Tawil: study concept and design, acquisition of data, analysis or interpretation of data, drafting/revising the manuscript, critical revision of the manuscript for important intellectual content, study supervision. John Kissel: acquisition of data, analysis or interpretation of data, critical revision of the manuscript for important intellectual content. Chad Heatwole: acquisition of data, analysis or interpretation of data, critical revision of the manuscript for important intellectual content. Shree Pandya: acquisition of data, analysis or interpretation of data, critical revision of the manuscript for important intellectual content. Gary Gronseth: study concept and design, acquisition of data, analysis or interpretation of data, study supervision. Michael Benatar: study concept and design, acquisition of data, analysis or interpretation of data, drafting/revising the manuscript, critical revision of the manuscript for important intellectual content, study supervision.

\section{STUDY FUNDING}

Supported by grant DD10-1012 from the Centers for Disease Control and Prevention. The findings and conclusions in this report are those of the authors and do not necessarily represent the official position of the Centers for Disease Control and Prevention. The remaining funding was provided by the American Academy of Neurology.

\section{DISCLOSURE}

R. Tawil has served as a consultant for aTyr Pharma, Cytokinetics Inc., and Novartis; and received research funding support from the NIH and the FSH Society. J. Kissel served on a scientific advisory board for and received travel funding from Cytokinetics. C. Heatwole receives research funding support from the NIH and the New York State Empire Clinical Research Investigator Program. S. Pandya, G. Gronseth, and M. Benatar report no disclosures relevant to the manuscript. Go to Neurology.org for full disclosures.

\section{DISCLAIMER}

Clinical practice guidelines, practice advisories, systematic reviews, and other guidance published by the American Academy of Neurology and its affiliates are assessments of current scientific and clinical information provided as an educational service. The information (1) should not be considered inclusive of all proper treatments, methods of care, or as a statement of the standard of care; (2) is not continually updated and may not reflect the most recent evidence (new evidence may emerge between the time information is developed and when it is published or read); (3) addresses only the question(s) specifically identified; (4) does not mandate any particular course of medical care; and (5) is not intended to substitute for the independent professional judgment of the treating provider, as the information does not account for individual variation among patients. In all cases, the selected course of action should be 
considered by the treating provider in the context of treating the individual patient. Use of the information is voluntary. AAN provides this information on an "as is" basis, and makes no warranty, expressed or implied, regarding the information. AAN specifically disclaims any warranties of merchantability or fitness for a particular use or purpose. AAN assumes no responsibility for any injury or damage to persons or property arising out of or related to any use of this information or for any errors or omissions.

\section{CONFLICT OF INTEREST}

The American Academy of Neurology and American Association of Neuromuscular \& Electrodiagnostic Medicine are committed to producing independent, critical, and truthful clinical practice guidelines (CPGs). Significant efforts are made to minimize the potential for conflicts of interest to influence the recommendations of this CPG. To the extent possible, the AAN and AANEM keep separate those who have a financial stake in the success or failure of the products appraised in the CPGs and the developers of the guidelines. Conflict of interest forms were obtained from all authors and reviewed by an oversight committee prior to project initiation. AAN and AANEM limit the participation of authors with substantial conflicts of interest. The AAN and AANEM forbid commercial participation in, or funding of, guideline projects. Drafts of the guideline have been reviewed by at least 3 AAN committees, at least 1 AANEM committee, a network of neurologists, Neurology ${ }^{\circledR}$ peer reviewers, and representatives from related fields. The AAN Guideline Author Conflict of Interest Policy can be viewed at www.aan.com. For complete information on this process, access the 2004 AAN process manual. ${ }^{22}$

Received October 27, 2014. Accepted in final form January 21, 2015.

\section{REFERENCES}

1. Padberg GW. Facioscapulohumeral Disease. Leiden: University of Leiden; 1982.

2. Flanigan KM, Coffeen CM, Sexton L, Stauffer D, Brunner S, Leppert MF. Genetic characterization of a large, historically significant Utah kindred with facioscapulohumeral dystrophy. Neuromuscul Disord 2001;11: 525-529.

3. Tawil R, Van Der Maarel SM. Facioscapulohumeral muscular dystrophy. Muscle Nerve 2006;34:1-15.

4. The FSH-DY Group. A prospective, quantitative study of the natural history of facioscapulohumeral muscular dystrophy (FSHD): implications for therapeutic trials. Neurology 1997;48:38-46.

5. Stübgen JP, Stipp A. Facioscapulohumeral muscular dystrophy: a prospective study of weakness and functional impairment. J Neurol 2010;257:1457-1464.

6. Wijmenga C, Brouwer OF, Padberg GW, Frants RR. Transmission of de-novo mutation associated with facioscapulohumeral muscular dystrophy. Lancet 1992;340: 985-986.

7. van Deutekom JC, Wijmenga C, van Tienhoven EA, et al. FSHD associated DNA rearrangements are due to deletions of integral copies of a $3.2 \mathrm{~kb}$ tandemly repeated unit. Hum Mol Genet 1993;2:2037-2042.

8. Lemmers RJ, de Kievit P, Sandkuijl L, et al. Facioscapulohumeral muscular dystrophy is uniquely associated with one of the two variants of the $4 \mathrm{q}$ subtelomere. Nat Genet 2002;32:235-236.

9. Gabriels J, Beckers MC, Ding $\mathrm{H}$, et al. Nucleotide sequence of the partially deleted D4Z4 locus in a patient with FSHD identifies a putative gene within each $3.3 \mathrm{~kb}$ element. Gene 1999;236:25-32.

10. Lyle R, Wright TJ, Clark LN, Hewitt JE. The FSHDassociated repeat, D4Z4, is a member of a dispersed family of homeobox-containing repeats, subsets of which are clustered on the short arms of the acrocentric chromosomes. Genomics 1995;28:389-397.

11. Lemmers RJ, van der Vliet PJ, Klooster R, et al. A unifying genetic model for facioscapulohumeral muscular dystrophy. Science 2010;329:1650-1653.

12. Snider L, Geng LN, Lemmers RJ, et al. Facioscapulohumeral dystrophy: incomplete suppression of a retrotransposed gene. PLoS Genet 2010;6:e1001181.

13. de Greef JC, Lemmers RJ, van Engelen BG, et al. Common epigenetic changes of D4Z4 in contractiondependent and contraction-independent FSHD. Hum Mutat 2009;30:1449-1459.

14. de Greef JC, Lemmers RJ, Camaño P, et al. Clinical features of facioscapulohumeral muscular dystrophy 2 . Neurology 2010;75:1548-1554.

15. Lemmers RJ, Tawil R, Petek LM, et al. Digenic inheritance of an SMCHD1 mutation and an FSHD-permissive D4Z4 allele causes facioscapulohumeral muscular dystrophy type 2. Nat Genet 2012;44:1370-1374.

16. Tawil R, van der Maarel SM, Tapscott SJ. Facioscapulohumeral dystrophy: the path to consensus on pathophysiology. Skelet Muscle 2014;4:12.

17. Tawil R, van der Maarel S, Padberg GW, van Engelen BG. 171st ENMC international workshop: Standards of care and management of facioscapulohumeral muscular dystrophy. Neuromuscul Disord 2010;20:471-475.

18. Attarian S, Salort-Campana E, Nguyen K, Behin A, Andoni Urtizberea J. Recommendations for the management of facioscapulohumeral muscular dystrophy in 2011. Rev Neurol 2012;168:910-918.

19. Narayanaswami P, Weiss M, Selcen D, et al. Evidencebased guideline summary: diagnosis and treatment of limb-girdle and distal dystrophies: report of the Guideline Development Subcommittee of the American Academy of Neurology and the Practice Issues Review Panel of the American Association of Neuromuscular \& Electrodiagnostic Medicine. Neurology 2014;83:1453-1463.

20. Kang PB, Morrison L, Iannaccone ST, et al. Evidence-based guideline summary: evaluation, diagnosis, and management of congenital muscular dystrophy: report of the Guideline Development Subcommittee of the American Academy of Neurology and the Practice Issues Review Panel of the American Association of Neuromuscular \& Electrodiagnostic Medicine. Neurology 2015;84:1369-1378.

21. Padberg GW, Lunt PW, Koch M, Fardeau M. Diagnostic criteria for facioscapulohumeral muscular dystrophy. Neuromuscul Disord 1991;1:231-234.

22. American Academy of Neurology. Clinical Practice Guidelines Process Manual, 2004 ed. St. Paul, MN: The American Academy of Neurology; 2004. Available at: https://www.aan.com/Guidelines/Home/Development. Accessed February 12, 2012.

23. American Academy of Neurology. Clinical Practice Guidelines Process Manual, 2011 ed. St. Paul, MN: The American Academy of Neurology; 2011. Available at: https://www.aan.com/ Guidelines/Home/Development. Accessed February 12, 2012.

24. Hsu YD, Kao MC, Shyu WC, et al. Application of chromosome 4q35-qter marker (pFR-1) for DNA rearrangement of facioscapulohumeral muscular dystrophy patients in Taiwan. J Neurol Sci 1997;149:73-79.

25. Funakoshi M, Goto K, Arahata K. Epilepsy and mental retardation in a subset of early onset 4q35facioscapulohumeral muscular dystrophy. Neurology 1998;50:1791-1794. 
26. Zeng Y, Zhang C, Su Q. Gene diagnosis of facioscapulohumeral muscular dystrophy [in Chinese]. Zhonghua Yi Xue Yi Chuan Xue Za Zhi 2001;18:213-215.

27. Goto K, Lee JH, Matsuda C, et al. DNA rearrangements in Japanese facioscapulohumeral muscular dystrophy patients: clinical correlations. Neuromuscul Disord 1995;5: 201-208.

28. Scionti I, Greco F, Ricci G, et al. Large-scale population analysis challenges the current criteria for the molecular diagnosis of fascioscapulohumeral muscular dystrophy. Am J Hum Genet 2012;90:628-635.

29. Ricci E, Galluzzi G, Deidda G, et al. Progress in the molecular diagnosis of facioscapulohumeral muscular dystrophy and correlation between the number of KpnI repeats at the $4 \mathrm{q} 35$ locus and clinical phenotype. Ann Neurol 1999;45:751-757.

30. Lemmers RJ, Wohlgemuth M, van der Gaag KJ, et al. Specific sequence variations within the $4 \mathrm{q} 35$ region are associated with facioscapulohumeral muscular dystrophy. Am J Hum Genet 2007;81:884-894.

31. Spurlock G, Jim HP, Upadhyaya M. Confirmation that the specific SSLP microsatellite allele 4qA161 segregates with fascioscapulohumeral muscular dystrophy (FSHD) in a cohort of multiplex and simplex FSHD families. Muscle Nerve 2010;42:820-821.

32. Köhler J, Röhrig D, Bathke KD, Koch MC. Evaluation of the facioscapulohumeral muscular dystrophy (FSHD1) phenotype in correlation to the concurrence of $4 \mathrm{q} 35$ and 10q26 fragments. Clin Genet 1999;55:88-94.
33. Statland JM, Tawil R. Risk of functional impairment in facioscapulohumeral muscular dystrophy. Muscle Nerve 2014;49:520-527.

34. Lunt PW, Jardine PE, Koch M, et al. Phenotypicgenotypic correlation will assist genetic counseling in 4q35-facioscapulohumeral muscular dystrophy. Muscle Nerve Suppl 1995;S103-S109.

35. Tawil R, Forrester J, Griggs RC, et al. Evidence for anticipation and association of deletion size with severity in facioscapulohumeral muscular dystrophy: The FSH-DY Group. Ann Neurol 1996;39:744-748.

36. Sakellariou P, Kekou K, Fryssira H, et al. Mutation spectrum and phenotypic manifestation in FSHD Greek patients. Neuromuscul Disord 2012;22:339-349.

37. Wohlgemuth M, van der Kooi EL, van Kesteren RG, van der Maarel SM, Padberg GW. Ventilatory support in facioscapulohumeral muscular dystrophy. Neurology 2004; 63:176-178.

38. Kilmer DD, Abresch RT, McCrory MA, et al. Profiles of neuromuscular diseases. Facioscapulohumeral muscular dystrophy. Am J Phys Med Rehabil 1995;74(5 suppl): S131-S139.

39. de Visser M, de Voogt WG, la Rivière GV. The heart in Becker muscular dystrophy, facioscapulohumeral dystrophy, and Bethlem myopathy. Muscle Nerve 1992;15:591-596.

40. Stevenson WG, Perloff JK, Weiss JN, Anderson TL. Facioscapulohumeral muscular dystrophy: evidence for selective, genetic electrophysiologic cardiac involvement. J Am Coll Cardiol 1990;15:292-299.

\section{This Week's Neurology ${ }^{\circledR}$ Podcast}

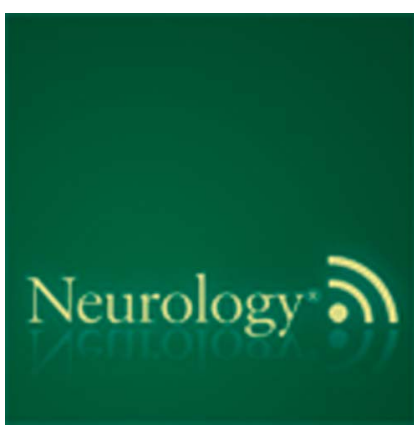

Evidence-based guideline: Evaluation, diagnosis, and management of facioscapulohumeral muscular dystrophy (see p. 357)

This podcast begins and closes with Dr. Robert Gross, Editor-inChief, briefly discussing highlighted articles from the July 28, 2015, issue of Neurology. In the second segment, Dr. Ted Burns talks with Dr. Rabi Tawil about the AAN guideline on the evaluation, diagnosis, and management of facioscapulohumeral muscular dystrophy. Dr. Sarah Wesley reads the e-Pearl of the week about vertical nystagmus. In the next part of the podcast, Dr. Alberto Espay focuses his interview with Dr. Helen Mayberg on her Robert Wartenberg Lecture at the AAN Annual Meeting on the topic of what deep brain stimulation has taught us about the neurology of depression.

Disclosures can be found at Neurology.org.

At Neurology.org, click on "RSS" in the Neurology Podcast box to listen to the most recent podcast and subscribe to the RSS feed.

CME Opportunity: Listen to this week's Neurology Podcast and earn 0.5 AMA PRA Category 1 CME Credits ${ }^{\mathrm{TM}}$ by answering the multiple-choice questions in the online Podcast quiz. 


\section{Neurology}

Evidence-based guideline summary: Evaluation, diagnosis, and management of facioscapulohumeral muscular dystrophy: Report of the Guideline Development, Dissemination, and Implementation Subcommittee of the American Academy of Neurology and the Practice Issues Review Panel of the American Association of Neuromuscular \& Electrodiagnostic Medicine

Rabi Tawil, John T. Kissel, Chad Heatwole, et al. Neurology 2015;85;357-364

DOI 10.1212/WNL.0000000000001783

This information is current as of July 27, 2015

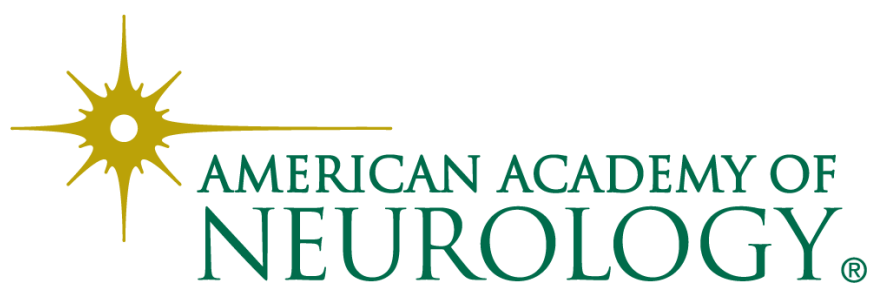




\section{Updated Information \& Services}

\section{Supplementary Material}

\section{References}

Citations

Subspecialty Collections

Permissions \& Licensing

Reprints including high resolution figures, can be found at: http://n.neurology.org/content/85/4/357.full

Supplementary material can be found at: http://n.neurology.org/content/suppl/2015/07/24/WNL.0000000000001 783.DC2 http://n.neurology.org/content/suppl/2015/07/24/WNL.0000000000001 783.DC1

This article cites 36 articles, 7 of which you can access for free at: http://n.neurology.org/content/85/4/357.full\#ref-list-1

This article has been cited by 7 HighWire-hosted articles: http://n.neurology.org/content/85/4/357.full\#\#otherarticles

This article, along with others on similar topics, appears in the following collection(s):

\section{All Genetics}

http://n.neurology.org/cgi/collection/all_genetics

Muscle disease

http://n.neurology.org/cgi/collection/muscle_disease

Information about reproducing this article in parts (figures,tables) or in its entirety can be found online at:

http://www.neurology.org/about/about_the_journal\#permissions

Information about ordering reprints can be found online:

http://n.neurology.org/subscribers/advertise

Neurology ${ }^{\circledR}$ is the official journal of the American Academy of Neurology. Published continuously since 1951, it is now a weekly with 48 issues per year. Copyright (C 2015 American Academy of Neurology. All rights reserved. Print ISSN: 0028-3878. Online ISSN: 1526-632X.

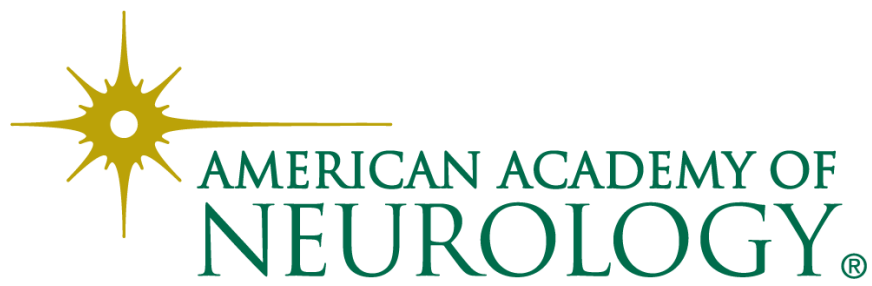

